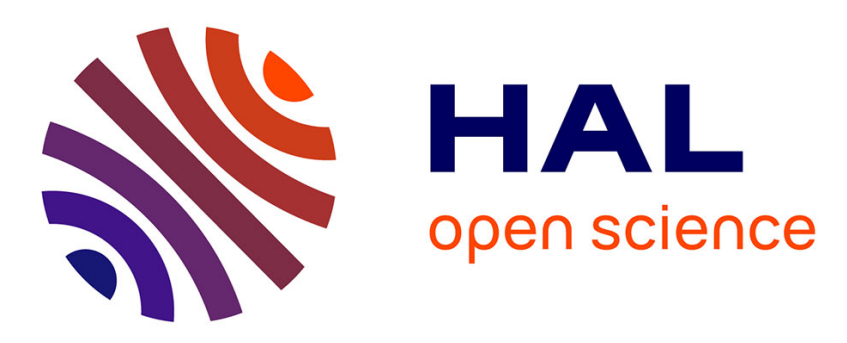

\title{
Detection of regularities in a random environment
}

Arnaud R Rey, Louisa Bogaerts, Laure Tosatto, Guillem Bonafos, Ana

Franco, Benoit Favre

\section{To cite this version:}

Arnaud R Rey, Louisa Bogaerts, Laure Tosatto, Guillem Bonafos, Ana Franco, et al.. Detection of regularities in a random environment. Quarterly Journal of Experimental Psychology, 2020, pp.174702182094135. 10.1177/1747021820941356 . hal-02943212

\section{HAL Id: hal-02943212 \\ https://hal.science/hal-02943212}

Submitted on 12 Nov 2020

HAL is a multi-disciplinary open access archive for the deposit and dissemination of scientific research documents, whether they are published or not. The documents may come from teaching and research institutions in France or abroad, or from public or private research centers.
L'archive ouverte pluridisciplinaire HAL, est destinée au dépôt et à la diffusion de documents scientifiques de niveau recherche, publiés ou non, émanant des établissements d'enseignement et de recherche français ou étrangers, des laboratoires publics ou privés. 
$11{ }^{1}$ Laboratoire de Psychologie Cognitive, CNRS \& Aix-Marseille University, France

$12{ }^{2}$ Institute of Language, Communication and the Brain, Aix-Marseille University, France

$13{ }^{3}$ Hebrew University, Jerusalem, Israel

$14{ }^{4}$ Center for Research in Cognition \& Neurosciences, Free University of Brussels, Belgium

$15{ }^{5}$ Laboratoire d'Informatique Fondamentale, CNRS \& Aix-Marseille University, France

18 Running head: REGULARITY DETECTION

$21 *$ Corresponding author:

22 Arnaud Rey

23 Laboratoire de Psychologie Cognitive

24 CNRS - Aix-Marseille Université

25 3, place Victor Hugo - Case D

2613331 Marseille Cedex 3

27 France

28 E-mail: arnaud.rey@univ-amu.fr 
REGULARITY DETECTION

$\underline{\text { Abstract }}$

32 Regularity detection, or statistical learning, is regarded as a fundamental component of our

33 cognitive system. To test the ability of human participants to detect regularity in a more

34 ecological situation (i.e., mixed with random information), we used a simple letter-naming

35 paradigm in which participants were instructed to name single letters presented one at a time

36 on a computer screen. The regularity consisted of a triplet of letters that were systematically

37 presented in that order. Participants were not told about the presence of this regularity. A

38 variable number of random letters were presented between two repetitions of the regular

39 triplet making this paradigm similar to a Hebb repetition task. Hence, in this Hebb-naming

40 task, we predicted that if any learning of the triplet occurred, naming times for the predictable

41 letters in the triplet would decrease as the number of triplet repetitions increased.

42 Surprisingly, across four experiments, detection of the regularity only occurred under very

43 specific experimental conditions and was far from a trivial task. Our study provides new

44 evidence regarding the limits of statistical learning and the critical role of contextual

45 information in the detection (or not) of repeated patterns. 
REGULARITY DETECTION

Detection of Regularities in a Random Environment

We often encounter the same objects, symbols, sounds and sensations time and time

again, and they tend to show up in a variety of contexts. One of the basic functions

underlying human cognitive processes is our ability to detect such invariant or regular

information within environmental variations. Regularity detection, also often labelled

statistical learning (SL), implicit learning, or implicit statistical learning (Christiansen, 2019;

Monaghan \& Rebuschat, 2019; Perruchet \& Pacton, 2006; Thiessen, Kronstein, \& Hufnagle,

2013; Rey, Minier, Malassis, Bogaerts, \& Fagot, 2018) is commonly assumed to be a gradual

process by which individuals experience a patterned sensory input and, by mere repeated

exposure to this regularity, implicitly derive knowledge of its underlying structure, using it to update their predictions of future events (e.g., Fine \& Jaeger, 2013; Misyak, Christiansen, \& Tomblin, 2010).

Standard SL tasks involve a visual or auditory familiarization stream, comprising a set of regularities, that is usually followed by an offline test phase (e.g., Aslin, Saffran, \&

62 Newport, 1998; Fiser \& Aslin, 2001; Reber, 1967; Saffran, Aslin \& Newport, 1996). In the

63 test phase, participants are asked to judge the familiarity of sequences that are either

64 consistent or inconsistent with the familiarization stream. The test score captures the total amount of learning that occurred by the end of the familiarization phase (see Siegelman, Bogaerts, Christiansen, \& Frost, 2016). The seminal findings of Saffran and colleagues inspired a large research community to focus on the ability to extract adjacent patterns of visual or auditory input, with little variation in the information contained in the stream. In

69 most experiments, therefore, the familiarization phase featured a set of regular patterns of different kinds that were combined in a semirandom manner to form a continuous familiarization stream (e.g., 11 syllables arranged in six triplets; Batterink, Reber, Neville, \& 
72 Paller, 2015; 24 abstract shapes arranged in eight triplets; Bogaerts, Siegelman, \& Frost,

732016 ; 12 aliens arranged in four triplets; Arciuli \& Simpson, 2012).

The present study featured a slightly different situation - possibly slightly more

ecological - in which a single regular pattern was inserted into random information.

Participants were shown a series of single letters displayed one at a time in the centre of a computer screen, and were simply instructed to name each letter. A single triplet of letters repeatedly appeared, in between random sequences of other letters. Participants were not, however, informed about the presence of a repeated pattern. If participants started to anticipate the predictable letters in the triplet (i.e., the second and third letters for which the transitional probability was equal to 1 ), then naming onsets for these letters would gradually decrease over time.

The presentation of a single regularity interspersed by noise sequences is very similar to the Hebb repetition task (Hebb, 1961). Hebb asked his participants to perform an immediate serial recall task in which one specific supraspan sequence was repeated every third trial. He found that the recall performances improved with the repetition of the regular pattern (for more recent studies using the Hebb task, see Bogaerts, Siegelman, Ben-Porat, \& Frost, 2017; Ordonez Magro, Attout, Majerus, \& Szmalec, 2018; Page \& Norris, 2009; Szmalec, Duyck, Vandierendonck, Mata, \& Page, 2009). Our experimental paradigm differed

90 from the Hebb task on the nature of the regularity (letter triplet vs. supraspan sequence of 91 items), the process elicited by the task (serial recall vs. naming), and the dependent variable

92 (recall performance vs. response times). However, due to its similarities with the Hebb repetition task, it could be identified as a "Hebb-naming task".

95 offline tasks has two main advantages. First, if learning is observed with standard SL tasks, it

96 is usually difficult to determine what has been learned exactly (e.g., did participants learn a 
97 little about each of the patterns, or did they pick up on just a few? see Siegelman, Bogaerts,

98 Armstrong, \& Frost, 2019), whereas the answer to that question should be more

99 straightforward in the present situation. Second, the naming task could serve as an online

100 learning measure, allowing us to trace the trajectory of learning. The reasoning here was that

101 if participants managed to extract the regularity, the predictability of its constituent elements

102 would increase over time (i.e., with repeated presentations of the regularity), leading to a

103 decrease in naming latencies for predictable letters. By looking at the change in naming

104 latencies across repeated presentations of the regularity, we would be able to study the

105 temporal dynamics of regularity detection under different learning conditions.

106 Although the idea of using naming as an online measure of regularity detection is

107 relatively novel, the idea of measuring regularity extraction online is not. Several recent

108 studies have used other novel behavioural experimental strategies to track learning as it

109 unfolds, in both SL and artificial grammar learning (AGL) paradigms. These strategies

110 typically involve asking participants to detect a target (e.g., Batterink, 2017; Gómez, Bion, \&

111 Mehler, 2011; Turk-Browne, Jungé, \& Scholl, 2005) or presenting an auditory sequence

112 where the participants' task is to select the written equivalent of the auditory stimuli from a

113 grid of options on the monitor (e.g., Dale, Duran, \& Morehead, 2012; Misyak et al., 2010).

114 Additional examples are self-paced SL and AGL tasks (Karuza, Farmer, Fine, Smith, \&

115 Jaeger, 2014; Siegelman, Bogaerts, Kronefeld, \& Frost, 2016), in which participants follow

116 the familiarization sequence at their own speed. In all these paradigms, faster button press or

117 mouse click responses for predictable stimuli than for unpredictable stimuli are assumed to be

118 an indication of (implicit) regularity learning ${ }^{1}$.

119 We know from the extensive SL, AGL and implicit learning literature that individuals

120 are able to extract structure, and two main theoretical approaches to regularity learning have

\footnotetext{
${ }^{1}$ Several studies also used EEG recordings to track online changes in event-related potentials when participants are exposed to an artificial language (e.g., Abla, Katahira, \& Okanoya, 2008; François et al., 2017; RodríguezFornells, Cunillera, Mestres-Missé, \& de Diego-Balaguer, 2009).
} 
121 been applied to date: the bracketing approach and the clustering approach (Swingley, 2005;

122 see also Frank, Goldwater, Griffiths, \& Tenenbaum, 2010). The bracketing approach, with

123 the simple recurrent network (SRN, Elman, 1990) as its most famous computational instance,

124 assumes that we learn to predict the next stimulus in a given context, based on the transitional

125 probabilities between sequence elements. The clustering approach, by contrast, assumes that

126 sensitivity to co-occurrences arises from the chunking that results from the repetition of

127 groups of elements. PARSER (Perruchet \& Vinter, 1998) and TRACX (French, Addyman, \&

128 Mareschal, 2011) are probably the best known models instantiating this approach (see also

129 McCauley \& Christiansen, 2019).

130 Although they assume different learning mechanisms, these approaches are actually

131 quite hard to tell apart, as they make similar predictions regarding most experimental SL

132 settings. Interestingly, they do make different predictions regarding the temporal dynamics of

133 learning small regular sequences embedded within larger ones (e.g., a sequence of three

134 items, $\mathrm{ABC}$, where A was consistently followed by B, and $\mathrm{B}$ by $\mathrm{C}$ ). Based on the assumption

135 that prior contextual information can influence pattern extraction, the $S R N$ model predicts an

136 advantage for the final part of an embedded sequence (e.g., slower learning of the first two

137 items than of the final one). By contrast, PARSER assumes that the input material is subjected

138 to random attentional exploration, and predicts that there will be no difference between the

139 beginning and end of the sequence. TRACX assumes that chunks are constructed on a left-to-

140 right basis, leading to the prediction that $\mathrm{AB}$ will be learned before $\mathrm{BC}$.

141 Evidence accumulated over the past decade supports the chunking approach (e.g.,

142 Giroux \& Rey, 2009; Orbán, Fiser, Aslin, \& Lengyel, 2008; but see also Franco \&

143 Destrebecqz, 2012), and TRACX has been proved to outperform the other models in

144 simulating several benchmark effects of regularity extraction (French et al., 2011). However,

145 the results of some recent studies have highlighted new constraints for chunking-based 
146 models (Kim, Seitz, Feenstra, \& Shams, 2009; Turk-Browne et al., 2005; see also Minier,

147 Fagot, \& Rey, 2016, for similar results in baboons). These studies of learning 3-item patterns

148 found that $\mathrm{C}$ is learned faster than $\mathrm{B}$, which can be interpreted as an effect of the strong

149 contextual information $\mathrm{AB}$ preceding $\mathrm{C}$, compared with the weaker contextual information $\mathrm{A}$

150 preceding B. This can be accounted for by an associative learning mechanism, but runs

151 counter to the predictions by the aforementioned chunking models. However, to date, it is not

152 clear whether the learning advantage for the final stimulus in a repeated pattern is observed in

153 other learning situations, such as the extraction of a single regular pattern hidden in noise.

154 The first goal of the present set of experiments was therefore to study the detection dynamics

155 of a regular letter triplet and to test the replicability of previous findings showing faster

156 learning for the letter in the last position of the triplet (i.e., C) compared with the one in the 157 second position (i.e., B).

158 The second goal was to ask how regularity extraction is influenced by different

159 learning conditions, that is, how do the characteristics of the pattern and its environment

160 affect learning? Interestingly, SL models (e.g., SRN, PARSER or TRACX) state that if the

161 contextual information is made up of different elements of the regular pattern, then the

162 critical factors for detecting this regularity will be the number of repetitions and the amount

163 of interfering information inserted between two repetitions of the regular pattern. With a

164 sufficient number of repetitions and a limited amount of interfering information, these models

165 therefore predict that participants will have no difficulty detecting the regular pattern. We

166 examined whether the evidence yielded by the present set of experiments supported this

167 claim.

168 Overview of the Experiments

169 Our study comprised four experiments. Experiment 1 tested the extraction of a

170 repeated triplet made up of consonants that alternated with random noise (sequences of two to 
171 five letters, randomly selected from a set of five different consonants). Experiment 2 tested

172 the extraction of a similar statistical regularity, but in contrast to the first experiment, the

173 repeated triplet was made up of vowels. In Experiment 3, we changed the nature of the

174 random (i.e., unstructured) noise separating the triplet repetitions, such that although the

175 noise sequences were still two to five letters long, these were drawn from a set of 14

176 consonants. Finally, Experiment 4 was identical to Experiment 3, except that the random

177 sequences between repetitions of the triplet were shorter (no more than three letters). The

178 data yielded by these four experiments are available on Open Science Framework at

179 https://osf.io/dyb4u/?view only=d35620f91740450b9a915643f6c49308.

180

\section{Experiment 1}

$181 \quad$ Method

$\underline{\text { Participants }}$

A total of 21 adults ( 7 men, 14 women; $M_{\text {age }}=20.15$ years), all native French speakers and students at Aix-Marseille University, took part in the study in exchange for a course credit. All reported normal or corrected-to-normal vision, and none reported a history of attention problems or reading disabilities.

The experiment was run on a portable computer equipped with a serial response box and an Audio-Technica microphone. The microphone was fixed to an adjustable stand and

190 positioned approximately $3 \mathrm{~cm}$ from the participant's mouth.

191 The naming task, administered via E-Prime 2.0 (Schneider, Eschman, \& Zuccolotto, 192 2002), involved the sequential presentation of individual letters in 70-point Arial white font

193 in the centre of a black background. Participants were instructed to read aloud each letter as

194 fast as possible. Speech onset and accuracy were recorded for each letter. Accuracy was

195 scored by an experimenter present in the testing room, who scored errors but also (rare) 
REGULARITY DETECTION

196 microphone failures as incorrect responses. Each letter stayed on the screen until the

197 microphone was triggered at speech onset. The next letter then appeared after a fixed

198 interstimulus interval (ISI) of $800 \mathrm{~ms}$.

199 Participants first performed a microphone test, which also allowed them to familiarize

200 themselves with the task. The microphone test consisted of 12 randomly selected naming

201 trials. The actual rapid naming experiment consisted of 3 blocks of 100 trials (i.e., individual

202 letter presentations) each. The letter stream that participants were exposed to was constructed

203 from a set of printed consonants (F, H, L, M, N, P, R, S, T). Eight letters were randomly

204 drawn from this set for each participant: three letters were used for the repeated triplet, and

205 triplet repetitions ( 15 per block, 45 in total) were always separated by two to five random

206 consonants, chosen from the five remaining letters. Frequency was balanced across the noise

207 letters for each block of 100 trials. The repeated triplet was never a three-letter alphabetic run

208 (e.g., LMN) or a well-known (French) abbreviation. The letters making up the triplet and

209 their serial order were counterbalanced across participants.

210 Participants could take a break after every block. After Blocks 1 and 2, participants

211 received oral feedback telling them that they were performing well, but had to try to speed up

212 (this feedback was given independently of their actual performance or speed). In total, the

213 naming task lasted approximately 10-15 minutes.

214 All participants responded to a short questionnaire after completing the naming task.

215 In standard SL experiments participants are typically tested after the exposure phase with a 2-

216 alternative forced choice task, testing the recognition of regular patterns against different

217 foils. Given that our focus is on a learning situation with only one regular triplet, building a

218 2-AFC task was problematic because it would be impossible to control for the frequency of

219 the regular triplet and the foils. We therefore opted for a questionnaire to get information

220 about the participants' explicit knowledge of the regularity (acknowledging that this might be 
REGULARITY DETECTION

221 qualitatively different from the ability to recognise a regularity).

The experimenter asked them "Did you notice anything in particular in this

experiment? Yes/No" and, in case of a "Yes" answer, the follow-up question "Can you

explain what you noticed?" If participants reported noticing the repeated presentation of a

sequence or sequences of letters, they were asked "Can you recall which sequence(s) of

letters was repeated?" If the answer to the first question was "No", or participants provided

an explanation that was unrelated to the presence of repeated patterns, the experimenter

explicitly asked them "Did you notice the repetition of a sequence of letters? Yes/No" and

"Can you recall which sequence of letters was repeated?"

$230 \quad \underline{\text { Results }}$

Speech onset latency

Only trials with correct naming responses $(97.97 \%$ of the data) were analysed. Those

where the stimulus presentation onset was delayed by more than $10 \mathrm{~ms}$ were excluded

close to normal in our task ${ }^{2}$. Given that we expected anticipatory naming responses, we included fast responses, and excluded only 6 data points with a SOL exceeding $800 \mathrm{~ms}$.

First, to study the learning trajectory across triplet repetitions as a function of the

244 Foundation for Statistical Computing, 2009) to run a linear mixed model with SOL as the

\footnotetext{
${ }^{2}$ This was due to the presence of anticipatory responses that distorted to the left the usually right-skewed distribution.
} 
REGULARITY DETECTION

245 dependent variable. The fixed effect variables included in the model were position (1-3) and

246 repetition number (1-45), as well as their two-way interaction. Position was sum-coded

247 (Position 1: -1 1; Position 2: 1 0; Position 3: 0 1), and repetition was mean-centred here and

248 in all subsequent models. The model included the maximum random effect structure that

249 allowed convergence (Barr, 2013; Barr et al., 2013): SOL Position + Repetition +

250 Position:Repetition $(1+\text { Position }+ \text { Repetition }+ \text { Position:Repetition | Participant })^{3}$. In other

251 words, we had a random intercept for participant and a random by-participant slope for

252 position, repetition and the Position $\mathrm{x}$ Repetition interaction. It should be noted that triplet

253 learning was predicted to result in a main effect of position (with faster SOLs for predictable

$2542^{\text {nd }}$ and $3^{\text {rd }}$ positions) and a Position $x$ Repetition interaction.

255 The results of the model are summarized in Table 2. We only found a significant effect

256 of repetition, with the negative coefficient for this effect reflecting an acceleration (faster

257 SOLs) over the course of the experiment. Model comparison with a likelihood-ratio test

258 (following the guidelines established by Barr et al., 2013) revealed that neither the main

259 effect of position, $\chi^{2}(2)=0.58, p=0.75$, nor the Position $\mathrm{x}$ Repetition interaction effect, $\chi^{2}(2)$

$260=3.25, p=0.20$, significantly improved the model fit.

In a second analysis, we tested whether there was evidence for significant learning at

263 the group level for each of the blocks. Learning was quantified as the difference score

264 between mean log-transformed naming SOLs for unpredictable letters (Position 1) versus

265 predictable letters (Positions 2 and 3). As such, a positive score could be interpreted as

266 evidence for learning. We opted for the use of log-transformed SOLs (rather than the raw

\footnotetext{
${ }^{3}$ It should be noted that we did not include letter identity as a random effect in the model, as this would have led to many instances of nonconvergence (across the four experiments). Although this could potentially have left us with more unexplained variance, it was not a concern, as in each experiment, the triplets were either randomly selected for each participant and/or letter position was counterbalanced, ensuring that any biases for individual letters were averaged out.
} 


\section{REGULARITY DETECTION}

values) to control for the baseline differences in the speed of participants' naming responses

268 (see Siegelman et al., 2019). ${ }^{4}$ When we compared the mean learning difference score for each

269 of the three blocks (see Table 1) with the hypothetical mean 0 using a one-sample $t$ test, and

270 found no evidence of significant learning (i.e., mean SOL difference score significantly

271 greater than zero) in any of the blocks (all $t \mathrm{~s}>1$ and $p_{\text {one-tailed }}>.10$ ).

Questionnaire

Eight of the 21 participants reported noticing a repeated pattern. Only one of them

correctly recalled the triplet (i.e., all three letters in the right order), but five other participants

correctly reported one subsequence (either Letters $1 \& 2$ or Letters $2 \& 3$ ).

Discussion

Surprisingly, the results of this first experiment showed that there was no significant acceleration for predictable letters. Furthermore, SOLs were not influenced by the serial position of the letter within the triplet. A number of participants noticed the presence of a repeated sequence, but most were unable to accurately recall the triplet. Although the presence of the repeated triplet looked obvious from the point of view of the experimenters, experimental situation, in which attentional processing was oriented toward the naming of each letter, was apparently very limited for most participants.

\footnotetext{
${ }^{4}$ To exemplify the influence of the log transformation, let us consider two participants with a mean difference of $100 \mathrm{~ms}$ between unpredictable and predictable letters, but a different baseline SOL: P1 unpredictable $=500 \mathrm{~ms}$, predictable $=400 \mathrm{~ms} ; \mathrm{P} 2$ unpredictable $=300 \mathrm{~ms}$, predictable $=200 \mathrm{~ms}$. Because of the baseline difference, P2's relative acceleration for predictable stimuli was far greater. The difference between predictable and unpredictable stimuli after log-transforming the SOLs reflects this, with 0.22 for P1 and 0.41 for P2.
} 
REGULARITY DETECTION

287 its name, these models predict that the residual activation for Letter 1 generated at trial t-1

288 should enhance the activation of Letter 2 at trial $t$, merely through associative learning

289 mechanisms. With sufficient repetitions, these transient memory traces should be reinforced,

290 and the activation of Letter 1 should gradually come to predict and pre-activate the neural

291 population coding for Letter 2. Apparently, for the majority of participants, the present

292 experimental conditions were ineffective in producing this mandatory associative learning of

293 adjacent patterns, indicating that we reached the limit of these mechanisms here.

The three following experiments were conducted to clarify this surprising result. In

295 Experiment 2, we tested the extraction of a repeated triplet of vowels (e.g., A, O, U). Given

296 that the letters for the triplet were drawn from a different category than the set of random

297 letters, which were all consonants, we expected the repeated triplet to be more salient, and the

298 detection of the regularity more efficient.

\section{Experiment 2}

$300 \quad$ Method

Participants

A different sample of 21 native French adults ( 2 men, 19 women; $M_{\text {age }}=19.81$ years $)$

took part in the experiment in exchange for a course credit or payment. As in the previous experiment, all the participants had normal or corrected-to-normal vision, and none of them reported a history of attention problems or reading disabilities.

\section{$\underline{\text { Procedure and materials }}$}

The naming task procedure was identical to the one used in Experiment 1 . The material, however, was different, in that the regular triplet was made up of three vowels. We always used the same three vowels $(\mathrm{A}, \mathrm{O}, \mathrm{U})$, but their order was counterbalanced across participants. The regular triplet was inserted into a random sequence of consonants drawn

311 from a set of five consonants (F, L, N, R, S), and the triplet repetitions (15 per block) were 
REGULARITY DETECTION

312 always separated by two to five random consonants.

$314 \underline{\text { Results }}$

315 Only correct responses $(97.22 \%$ of the data) were analysed. Trials where the stimulus

316 presentation onset was delayed by more than $10 \mathrm{~ms}$ were excluded ( $0.98 \%$ of the data), as

317 were four data points with SOLs exceeding $800 \mathrm{~ms}$.

318 Table 3 summarizes the results of Experiment 2. The plot in Figure 3 suggests that

319 letter predictability had a strong effect on SOLs, and this was confirmed by the results of our 320 statistical analysis.

-- Figure 3 about here -

The mixed model used to analyse the data of Experiment 2 was identical to the model we used in Experiment 1. Its results are summarized in Table 4.

We found a significant effect of repetition, with the negative coefficient for this effect reflecting a decrease in SOLs. The coefficients for the effect of Position 3 reflect the fact that

328 SOLs were significantly faster for predictable Position 3 letters relative to the mean SOL across all positions. Finally, a significant negative interaction coefficient indicated a significantly greater acceleration for Position 3 letters relative to the mean acceleration across

331 all positions. Model comparison revealed that both the main effect of position, $\chi^{2}(2)=21.80$, $332 p<0.001$, and the Position $\mathrm{x}$ Repetition interaction effect, $\chi^{2}(2)=70.43, p<0.001$, were

333 significant. A follow-up analysis revealed that pairwise position contrasts were significant for 334 Position 1 - Position 2, $t(21.01)=4.58$, Tukey-adjusted $p<0.001$, and Position 1 - Position 3, $335 t(20.13)=5.99$, Tukey-adjusted $p<0.001$, but not for Position 2 - Position $3, t(19.97)=2.38$, 336 Tukey-adjusted $p=0.07)$. 
REGULARITY DETECTION

338 for unpredictable and predictable letters, we found strong evidence for learning even in the

339 first block, $t(20)=5.09, p_{\text {one-tailed }}<.001$, and learning increased further with exposure, $t(20)=$

$3403.21, p_{\text {one-tailed }}<.001$ for Block $2 ; t(20)=4.03, p_{\text {one-tailed }}<.001$ for Block $3(\text { see Table } 3)^{5}$.

\section{Questionnaire}

Nineteen of the 21 participants reported noticing a repeated pattern, and 14 of them correctly recalled the triplet. Two other participants correctly reported one subsequence

344 (Letters $1 \& 2$ or Letters $2 \& 3)$.

\section{Discussion}

The results of Experiment 2, in contrast to those of our first experiment, revealed clear

effects of predictability on SOLs. Shorter SOLs were observed for the second and third letters in the repeated triplet, and this difference increased across repetitions. Results further showed an increased naming advantage for Position 3 over Position 2-a pattern consistent with previous findings (e.g., Minier et al., 2016).

The use of different letter categories for the structured and unstructured material

352 (vowels in the triplet and consonants in the noise) may, of course, have served as a cue that

353 facilitated the parsing of the continuous sequence and the extraction of the regular triplet pattern. Participants' responses to the awareness questionnaire suggest that, for at least $90 \%$ of them, the resulting knowledge about the structure was conscious. This result therefore indicates that regularity detection is possible within this experimental paradigm, though only

357 if the regular triplet is made more salient than the random information. possible explanation is that the regularity was presented within noise that was still relatively

\footnotetext{
${ }^{5}$ It should be noted that we only compared predictable versus unpredictable vowels here, so even though vowels and consonants may not trigger the voice key in the same way (thus affecting SOLs), this could not bias our analyses.
} 
360 structured. That is, given that the noise letters were drawn from a set of just five consonants,

361 the theoretical mean transitional probability between the different noise letters was .25.

362 Participants' responses on the post-task questionnaire indicated that regularities were also

363 detected in the unstructured noise material. We tentatively suggest that the structure

364 perceived in the noise may have interfered with the extraction of the actual triplet. In

365 Experiment 3, we sought to increase the signal-to-noise ratio, without giving any cues for the

366 regular triplet. We tested whether we could find evidence for regularity detection in a

367 consonant-only version of the task using noisier noise. Therefore, instead of selecting them

368 from a set of five consonants, we drew the noise letters from a set of 14 consonants, making

369 the transitional probabilities between noise letters much smaller than they were in Experiment

$370 \quad 2$.

\section{Experiment 3}

Method

Participants

A sample of 22 native French speakers ( 7 men, 15 women; $M_{\text {age }}=21.73$ years) took part in the study in exchange for either a course credit or a payment.

The procedure was identical to the one used in Experiments 1 and 2. The letter stream was constructed with the full set of 20 French consonant letters minus W (referred to in French as double $V$ [double U], and the low-frequency letters Q and X (hence, a set of 17).

380 Three letters were used to construct the triplet (as before, the letter organization of the triplet

381 was counterbalanced across participants), while the 14 remaining letters were used for the unstructured noise. Triplet repetitions ( 15 per block) were always separated by two to five randomly structured consonants, as in the previous experiments. 
REGULARITY DETECTION

$\underline{\text { Results }}$

Only correct responses $(96.27 \%$ of the data) were analysed. Trials where the stimulus presentation onset was delayed by more than $10 \mathrm{~ms}$ were excluded ( $0.94 \%$ of the data). One participant was excluded from the analysis as she failed to give rapid naming responses. Her mean SOL for triplet letters (493.29 ms) exceeded the sample's mean $(391.26 \mathrm{~ms})+1.5^{*} S D$

389 (58.31 ms). learning effect, but a substantially smaller one than the effect we observed in Experiment 2. results of the model are summarized in Table 6 . approached the significance threshold $(\beta=-12.3$, CI $[-23.7,-0.9], p=.06)$ indicating that SOLs were faster for predictable Position 3 letters relative to the mean SOL across positions. Model comparisons revealed that the main effect of position was also approaching significance, $\chi^{2}(2)=5.66, p=.058$, while the Block $\mathrm{x}$ Position interaction did not significantly improve the model fit, $\chi^{2}(2)=2.49, p=.29$. A follow-up analysis contrasting

403 Position 1, 2 and 3 revealed similar trends: Position 1 - Position 2, $t(18.97)=1.81$, Tukey404 adjusted $p=0.19$; Position 1 - Position 3, $t(18.99)=2.49$, Tukey-adjusted $p=0.055$; Position $4052-$ Position $3, t(18.99)=1.69$, Tukey-adjusted $p=0.23$. 
407 underlying statistical structure of the letter stream - as reflected by a difference score

408 between SOLs for unpredictable and predictable letters that was significantly greater than

409 zero, $t(20)=.99, p_{\text {one-tailed }}=.17$. Significant learning was apparent in the subsequent learning

410 blocks: $t(20)=2.64, p_{\text {one-tailed }}<.01$ for Block 2 , and $t(20)=1.69, p_{\text {one-tailed }}=.05$ for Block 3

411 (see Table 5).

412 Questionnaire

Thirteen of the 21 participants reported noticing a recurrent letter sequence. Three of

414 them could recall the whole triplet, and two others correctly recalled one subsequence

415 (Letters $1 \& 2$ or Letters $2 \& 3$ ).

416 Discussion

417 In line with the results of Experiment 2, the difference in SOLs between unpredictable 418 and predictable letters increased across blocks. It should be noted that the online learning

419 effect was substantially smaller than the one observed for the vowel triplet. Significant

420 learning also emerged later (in the second block rather than in the very first). Unsurprisingly,

421 in the absence of any cue other than the statistical properties of the stream, far fewer

422 participants were able to explicitly recall the repeated triplet (3/21 vs. 14/21 for Experiment 423 2).

A key result of these first three experiments was that the context in which the regular patterns were presented influenced online learning performances. To account for the lack of online learning in our first experiment, we tentatively hypothesized that the statistical

427 structure in the noise interfered with the extraction of the actual triplet. The fact that we

428 found learning under nearly identical learning conditions, the only difference being the set of 429 letters used to construct the noise sequences, suggests that the degree of latent structure in the 
REGULARITY DETECTION

430 noise sequences affected the detection of the regularity ${ }^{6}$. This result is problematic for most

431 SL models. Recall of the letters making up the regular triplet should not have been affected

432 by the manipulation of the noise information in Experiment 3, and results should have been

433 the same as those in Experiment 1.

Previous research has demonstrated that learners form expectations about the kind of structure present in an information stream, based on previous exposure to other streams

436 (Lew-Williams \& Saffran, 2012), and may therefore fail to learn structures that conflict with

437 their expectations (Gebhart, Aslin, \& Newport, 2009). A similar conflict may occur within a

438 single stream when wrong expectations are formed on the basis of the noise information

439 (which was not sufficiently noisy in Experiment 1). In that case, participants may keep in

440 mind a random repetition (which is more likely to occur in Experiment 1 due to the small

441 number of filler letters) and this expectation may interfere with the discovery of the genuine

442 regularity. An alternative (though not necessarily mutually exclusive) interpretation relates to

443 memory constraints (Frank \& Gibson, 2011; Frank, Goldwater, Griffiths, \& Tenenbaum,

444 2010). The presence of quasi-regularities in the noise sequences may be disadvantageous if

445 they are being kept active in working memory. This could be especially true in the context of

446 a demanding task such as rapid naming that presumably takes up capacity itself.

In the fourth and final experiment, we aimed to determine the effect of reducing the

448 distance between occurrences of the regular pattern. All SL models predict that shorter noise

449 sequences between triplet repetitions should lead to improved learning.

\footnotetext{
${ }^{6}$ It should be noted that although the triplet was repeated the same number of times (45) in each of the experiments, the relative frequency of triplet letters versus noise letters was higher in Experiment 3 than in Experiment 1. This factor may have contributed to participants' better learning performances. Faster SOLs for Position 1 than for noise letters (see Fig. 5) suggest that participants also picked up on the greater frequency of the first letter in the triplet. However, given that the difference between unpredictable Position 1 and predictable Positions 2 and 3 increased, this frequency effect cannot fully account for the data.
} 
Method

\section{$\underline{\text { Participants }}$}

A sample of 24 native French speakers ( 4 men, 20 women; $M_{\text {age }}=20.1$ years $)$ took part in the study in exchange for a course credit.

\section{$\underline{\text { Procedure and materials }}$}

The procedure used in Experiment 4 was identical to the one used in Experiment 3,

As the total number of trials was identical to the number in the three previous experiments (300 trials in three blocks of 100 trials), there were 62 rather than 45 triplet repetitions.

$462 \underline{\text { Results }}$ were 11 data points with SOLs exceeding $800 \mathrm{~ms}$.

$$
\text { -- Figure } 5 \text { about here -- }
$$


REGULARITY DETECTION

475 SOLs were significantly faster for the predictable Position 3 compared with the mean across

476 all positions. Finally, the significant negative interaction coefficient indicated greater

477 acceleration for Position 3 across repetitions, relative to the mean acceleration for all

478 positions. Model comparisons revealed a significant main effect of position, $\chi^{2}(2)=12.82, p$

$479<.01$, and a significant Position $\mathrm{x}$ Repetition interaction, $\chi^{2}(2)=8.05, p=.018$. Pairwise

480 position contrasts were significant for Position 1 - Position 2, $t(23.02)=3.85$, Tukey-adjusted

$481 p<0.01$, and Position 1 - Position 3, $t(22.98)=3.647$, Tukey-adjusted $p<0.01$, but not for

482 Position 2 - Position 3, $t(22.94)=1.32$, Tukey-adjusted $p=0.40$.

One-sample $t$ tests revealed that participants already exhibited significant learning of

484 the underlying statistical structure of the letter stream in the first block, $t(23)=2.94, p_{\text {one-tailed }}$

$485<.01$, which remained significant in subsequent learning blocks, with $t(23)=2.89, p_{\text {one-tailed }}<$ 486.001 for Block 2, and $t(23)=3.84, p_{\text {one-tailed }}<.001$ for Block 3 (see Table 7).

To directly compare learning in the current experiment with learning in Experiment 3, we ran another linear mixed model on the data for the two experiments, subsetting the data of Experiment 4 to include only the first 45 repetitions. In this model, learning score was the dependent variable, and experiment, repetition and the Experiment $\mathrm{x}$ Repetition interaction were fixed effects with a random by-participant intercept. Experiment was sum-coded

492 (Experiment 3: -1; Experiment 4: 1). We found significant main effects of Experiment $(\beta=$ 493 0.04, $S E=0.01, p<.001)$ and Repetition $(\beta=0.005, S E=0.001, p<.001)$, and a significant interaction effect $(\beta=0.002, S E=0.001, p<.001)$, confirming stronger learning in 495 Experiment 4 than in Experiment 3 (see also Fig. 6).

497 Questionnaire 
REGULARITY DETECTION

could recall the whole triplet, while four others correctly recalled one subsequence (Letters

$500 \quad 1 \& 2$ or Letters $2 \& 3)$.

501

502

503

504

505

506

507

508

509

510

511

512

513

514

515

516

517

518

519

520

521

522

523

Discussion

In Experiment 4, we tested the prediction that shorter noise sequences between triplet repetitions would further improve learning in the naming task. Results showed that overall learning scores were indeed higher than in Experiment 3. With its 17 additional repetitions, the present experiment also provided information regarding the trajectory of SOLs in the later stages of pattern learning. Interestingly, the decrease in SOLs for predictable letters continued unabated across the 62 repetitions (no sign of reaching asymptote).

\section{General Discussion}

In the present study, participants had to name out loud single letters that were displayed one at a time on a computer screen. Unbeknownst to them, the stream contained a repeated letter triplet. Our data suggest that SOLs were sensitive to online statistical computations: with exposure, SOLs for the predictable second and third letters in the repeated triplet decreased. However, this effect was only present when the information stream had what could be described as a high signal-to-noise ratio. To be detected, the triplet either had to have a salient feature compared with the noise information (Exp. 2), or the noise sequences between successive presentations of the regular pattern had to be sufficiently noisy (Exp. 3) or short (Exp. 4). Otherwise, the regular pattern remained undetectable for most participants (Exp. 1).

Taken together, the results of our four experiments have two main implications for models of implicit SL. First, they show that although SL mechanisms are powerful, they also have limitations. The detection of co-occurrences and regularities does not systematically take place when participants are exposed to a repeated regular pattern of adjacent items, even if this pattern is relatively simple. Mere repetition is not a sufficient condition for a regularity 


\section{REGULARITY DETECTION}

524 to stand out from a stream of variable information, and for participants to detect it. The

525 regular pattern will be detected either because of a feature that makes it salient with respect to

526 the surrounding variable information (i.e., vowels vs. consonants; Exp. 2) or because the

527 mean interval between two repetitions is small enough for the memory trace of the co-

528 occurrences to be sufficiently reinforced (Exp. 4). This raises important issues, such as the

529 role of regularity learning in more natural contexts, as well as educational ones. In language

530 learning in particular, a field in which SL has become a dominant theoretical construct in

531 recent years, the current findings point to the limitations of our implicit co-occurrence

532 learning abilities.

533 Second, the present results indicate that the context or surrounding information in

534 which the regularities are presented may matter for SL (Exp. $1 \& 3$ ). If the variable context is

535 not variable enough, associative learning mechanisms may extract co-occurrences that have

536 sufficiently strong transitional probabilities, but which are irrelevant. This is an issue that has

537 so far received too little attention, as almost all previous research has used input streams with

538 a similar latent structure, repeating $n$ (usually between four and eight) triplets or pairs with a

539 transitional probability of 1 between the items within each one (Siegelman et al., 2016).

540 The present data also replicate previous findings on the dynamics of regularity

541 extraction. The results of Experiment 2, where we tested a vowel triplet in consonant noise,

542 revealed greater acceleration for Position 3 versus Position 2 letters, and we saw a similar

543 trend in Experiments 3 and 4. This could be interpreted as an effect of context on the learning

544 of the final stimulus in a repeated triplet (i.e., the final stimulus benefits from the contextual

545 information provided by the stimuli that consistently precede it), in line with the effect

546 described by Minier et al. (2016) in the motor sequence learning trajectory of baboons. It

547 therefore suggests that in a verbal SL task, greater contextual information facilitates

548 prediction (see also Rey, Minier, Malassis, Bogaerts, \& Fagot, 2018). As argued by Minier et 
REGULARITY DETECTION

549 al. (2016), this learning advantage for the final item or embedded pattern is predicted by the

550 SRN model, but poses challenges for chunking models such as PARSER, which predicts no

551 difference between learning for the initial (Letters $1 \& 2$ in a triplet) and final (Letters $2 \& 3$ )

552 embedded patterns, or TRACX, which predicts faster learning for the initial one (Letters

553 1\&2) - the opposite of what we found.

$554 \quad$ Prospects and limitations

555 We believe that the Hebb-naming paradigm described here offers a simple

556 behavioural approach to studying learning dynamics online, suitable for studying how fast

557 and with which trajectory learners capture the statistical properties of incoming sensory

558 information. It could be used to complement existing offline measures and might help to

559 overcome some of the psychometric shortcomings of offline measures, such as test

560 interference. As a more implicit and direct measure (see also Isbilen, Frost, Monaghan, \&

561 Christiansen, 2018), SOL might prove particularly useful for studying SL in young children

562 (e.g., Arnon, 2019; Lammertink, van Witteloostuijn, Boersma, Wijnen, \& Rispens, 2018) or

563 certain patient groups (e.g., amnesic patients; Schapiro, Gregory, Landau, McCloskey, \&

564 Turk-Browne, 2014) who have difficulty with the 2-AFC testing format. It also has a

565 considerable advantage (over for example the RT-based measure in an SRT task) due to the

566 many degrees of freedom in constructing the regular sequence (e.g., contrary to the SRT task,

567 it is possible to have several sequences with transitional probabilities of 1). It could be

568 employed with all sorts of nameable stimuli with large set sizes (e.g., pictures, words) and

569 with different types of regularities. By extension, this measure could also be included in

570 verbal AGL and Hebb repetition paradigms.

571 The above formulation "as a more implicit and direct measure" requires some further

572 clarification. We worked on the premise that faster SOLs for predictable letter stimuli can

573 occur when learning is implicit, that is, when the stream of letters is processed without "the 
574 conscious intention to find out whether the input information contains regularities" (Hulstijn, 575 2005, p. 131). However, this does not mean that the learning trajectories we observed were 576 uniquely shaped by implicit learning processes (Andringa \& Rebushat, 2015). In each of the

577 experiments, by the end of the task (i.e., after several dozen repetitions) several participants

578 displayed conscious knowledge of the regularity that had been learned, and the pattern of

579 questionnaire results across our four experiments suggests that either awareness emerged

580 with increased implicit learning, or some emerging awareness of the regularity (while

581 participants were engaged in the naming task) amplified the online learning effect as we

582 measured it. Splitting participants from Experiment 4 in two groups of similar sizes (i.e.,

583 participants who could recall $v s$. who could not recall the repeated sequence of letters (with $\mathrm{N}$

$584=13$ and $\mathrm{N}=11$, respectively), we indeed found that the interaction between Position 3 and

585 Repetition was significant for those who could recall the sequence $(\beta=-1.22$, CI [-2.06, -

$5860.37], p<.02)$ but not for the other group $(\beta=-0.51$, CI $[-1.23,0.21], p=0.191)$.

587 Although the present investigation goes some way toward the development of a Hebb

588 naming SL task, future research will have to examine whether the task can be adapted to

589 other types of verbal stimuli and to the auditory modality (where the participants are asked to

590 shadow rather than to name), and whether it can also be employed to study different types of

591 regularities (e.g., nonadjacent co-occurrences). Furthermore, from a psychometric

592 perspective, it is important to examine whether the online naming measure can reliably tap

593 into individual performances on the task and predict offline performance.

594 Conclusion

595 We asked participants to name letters presented in continuous letter sequences and

596 measured their SOLs in four experiments. Overall, our data suggest that SOLs are sensitive to

597 stimulus predictability and to online statistical computations. Our results also highlight the

598 influence of the context in which a regular pattern is presented, and a major limitation of 


\section{REGULARITY DETECTION}

599 implicit co-occurrence learning abilities in the context of an active naming task.

600 
REGULARITY DETECTION

601

602

603

604

605

606

607

608

609

610

611

612 None of the experiments were preregistered.

613

614

615

616

617

618

619

620

621

622

623

624 comparable ethical standards.

\section{$\underline{\text { Acknowledgements }}$}

This work was supported by the BLRI Labex (ANR-11-LABX-0036) and Institut

Convergence ILCB (ANR-16-CONV-0002) (grant awarded to Arnaud Rey and Benoit

Favre), as well as by the Fyssen Foundation, of which Louisa Bogaerts was a research fellow in 2015-2016. Louisa Bogaerts is currently funded by the European Union's Horizon 2020

research and innovation programme under the Marie Skłodowska-Curie Grant Agreement

No. 743528 (IF-EF). This research was also supported by the CHUNKED ANR project

(\#ANR-17-CE28-0013-02). We are grateful to Jay McClelland for the insightful discussions

that inspired some of the main ideas in this work.

\section{Open Practices Statements}

Data and materials for all the experiments are available on Open Science Framework.

\section{Conflict of Interest}

AR, LB, LT, GB, AF, and BF declare that they have no conflict of interest.

Ethical Approval

All procedures in the present experiments involving human participants were

performed in accordance with the ethical standards of the institutional and/or national

research committee and with the 1964 Declaration of Helsinki and its later amendments or

\section{$\underline{\text { Informed Consent }}$}

Informed consent was obtained from each of the participants included in the study. 


\section{REGULARITY DETECTION}

626 Abla, D., Katahira, K., \& Okanoya, K. (2008). On-line assessment of statistical learning by 627 event-related potentials. Journal of Cognitive Neuroscience, 20(6), 952-964.

628 Andringa, S., \& Rebuschat, P. (2015). New directions in the study of implicit and explicit 629 learning. Studies in Second Language Acquisition, 37(2), 185-196.

630 Arciuli, J., \& Simpson, I. (2012). Statistical learning is related to Reading Ability in Children 631 and Adults. Cognitive Science, 36(2), 286-304.

632 Arnon, I. (2019). Statistical learning, implicit learning and first language acquisition:

633 Evaluating the link between statistical learning measures and language outcomes. Topics $634 \quad$ in Cognitive Science, 11(3), 504-519.

635 Aslin, R. N., Saffran, J. R., \& Newport, E. L. (1998). Computation of conditional probability 636 statistics by 8-month-old infants. Psychological Science, 9, 321-324.

637 Barr, D. J. (2013). Random effects structure for testing interactions in linear mixed-effects 638 models. Frontiers in Psychology, 4, 328.

639 Barr, D. J., Levy, R., Scheepers, C., \& Tily, H. J. (2013). Random effects structure for 640 confirmatory hypothesis testing: Keep it maximal. Journal of Memory and Language, 68, 641 $255-278$

642 Batterink, L. (2017). Rapid statistical learning supporting word extraction from continuous speech. Psychological Science, 28(7), 921-928.

644 Batterink, L., Reber, P. J., Neville, H., \& Paller, K. A. (2015). Implicit and explicit contributions to statistical learning. Journal of Memory and Language, 83, 62-78.

646 Bogaerts, L., Siegelman, N., Ben-Porat, T. \& Frost, R. (2017): Is the Hebb repetition task a 647 reliable measure of individual differences in sequence learning? The Quarterly Journal 
REGULARITY DETECTION

649 Bogaerts, L., Siegelman, N., \& Frost, R. (2016). Splitting the variance of statistical learning 650 performance: A parametric investigation of exposure duration and transitional 651 probabilities. Psychonomic Bulletin \& Review, 23(4), 1250-1256.

652 Christiansen, M.H. (2019). Implicit-statistical learning: A tale of two literatures. Topics in 653 Cognitive Science, 11(3), 468-481.

654 Dale, R., Duran, N. D., \& Morehead, J. R. (2012). Prediction during statistical learning, and 655 implications for the implicit/explicit divide. Advances in Cognitive Psychology, 8(2), 196-209.

Durrant, S. J., Taylor, C., Cairney, S., \& Lewis, P. A. (2011). Sleep-dependent consolidation 658 of statistical learning. Neuropsychologia, 49(5), 1322-1331.

659 Elman, J. L. (1990). Finding structure in time. Cognitive Science, 14, 179-211.

660 Fine, A. B. \& Florian Jaeger, T. (2013), Evidence for implicit learning in syntactic 661 comprehension. Cognitive Science, 37, 578-591.

Fiser, J., \& Aslin, R. N. (2001). Unsupervised statistical learning of higher-order spatial structures from visual scenes. Psychological Science, 12, 499-504.

664 Franco, A., \& Destrebecqz, A. (2012). Chunking or not chunking? How do we find words in 665 artificial language learning? Advances in Cognitive Psychology, 8, 144.

666 François, C., Teixidó, M., Takerkart, S., Agut, T., Bosch, L., \& Rodriguez-Fornells, A. 667 (2017). Enhanced neonatal brain responses to sung streams predict vocabulary outcomes 668 by age 18 months. Scientific Reports, 7(1), 12451. 
669 Frank, M. C., \& Gibson, E. (2011). Overcoming memory limitations in rule learning. $670 \quad$ Language Learning and Development, 7, 130-148.

671 Frank, M. C., Goldwater, S., Griffiths, T., \& Tenenbaum, J. B. (2010). Modeling human 672 performance in statistical word segmentation. Cognition, 117, 107-125.

673 French, R. M., Addyman, C., \& Mareschal, D. (2011). TRACX: A recognition-based 674 connectionist framework for sequence segmentation and chunk extraction. Psychological $675 \quad$ Review, 118, 614-636.

676 Gebhart, A. L., Newport, E. L. \& Aslin, R. N. (2009). Statistical learning of adjacent and 677 nonadjacent dependencies among nonlinguistic sounds. Psychological Bulletin and $678 \quad$ Review, 16, 486-490.

679 Giroux, I., \& Rey, A. (2009). Lexical and sublexical units in speech perception. Cognitive $680 \quad$ Science, 33(2), 260-272.

681 Gómez, D. M., Bion, R. H., \& Mehler, J. (2011). The word segmentation process as revealed 682

Hebb, D. (1961). Distinctive features of learning in the higher animal. In J. F. Delafresnaye by click detection. Language, Cognition and Neuroscience, 26, 212-223.

Hulstijn, J. H. (2005). Theoretical and empirical issues in the study of implicit and explicit 686 second-language learning. Studies in Second Language Acquisition, 27, 129-140.

687 Isbilen, E. S., Frost, R. L. A, Monaghan, P., \& Christiansen, M .H. (2018). Bridging artificial 688 and natural language learning: Comparing processing- and reflection-based measures of 689 learning. In T. T. Rogers, M. Rau, X. Zhu, \& C. W. Kalish (Eds.), Proceedings of the 690 40th Annual Conference of the Cognitive Science Society (pp. 1856-1861). Austin, TX: Cognitive Science Society. 


\section{REGULARITY DETECTION}

692 Karuza, E. A., Farmer, T. A., Fine, A. B., Smith, F. X. \& Jaeger, T. F. (2014). On-line 693 measures of prediction in a self-paced statistical learning task. In Proceedings of the 36th 694 Annual Meeting of the Cognitive Science Society (pp. 725-730). Quebec City, Canada.

695 Kim, R., Seitz, A., Feenstra, H., \& Shams, L. (2009). Testing assumptions of statistical 696 learning: Is it long-term and implicit? Neuroscience Letters, 461(2), 145-149.

697 Lammertink, I., van Witteloostuijn, M., Boersma, P., Wijnen, F., \& Rispens, J. (2018).

698 Auditory statistical learning in children: Novel insights from an online measure. Applied $699 \quad$ Psycholinguistics. doi:10.1017/S0142716418000577

700 Lew-Williams, C., \& Saffran, J. R. (2012). All words are not created equal: Expectations 701 about word length guide infant statistical learning. Cognition, 122, 241-246.

702 McCauley, S. M., \& Christiansen, M. H. (2019). Language learning as language use: A cross703 linguistic model of child language development. Psychological Review, 126(1), 1-38.

704

705

Minier, L., Fagot, J., \& Rey, A. (2016). The temporal dynamics of regularity extraction in non-human primates. Cognitive Science, 40(4), 1019-1030.

Misyak, J. B., Christiansen, M. H., \& Tomblin, J. B. (2010). On-line individual differences in 707 statistical learning predict language processing. Frontiers in Psychology, 1, 31.

Rebuschat, P., \& Monaghan, P. (2019). Editors' introduction: Aligning implicit learning and statistical learning: Two approaches, one phenomenon. Topics in cognitive science, 11(3), 459-467.

711 Page, M., \& Norris, D. (2009). A model linking immediate serial recall, the Hebb repetition 712 effect and the learning of phonological word forms. Philosophical Transactions of the 713 Royal Society London B Biological Sciences, 364(1536), 3737-3753. doi:10.1098/rstb.2009.0173

715 Perruchet, P., \& Pacton, S. (2006). Implicit learning and statistical learning: One 
717 Perruchet, P., \& Vinter, A. (1998). PARSER: A model for word segmentation. Journal of $718 \quad$ Memory and Language, 39, 246-263.

719 Orbán, G., Fiser, J., Aslin, R. N., \& Lengyel, M. (2008). Bayesian learning of visual chunks 720 by human observers. Proceedings of the National Academy of Sciences, 105(7), 2745-2750.

722

723

724

Rey, A., Minier, L., Malassis, R., Bogaerts, L., \& Fagot, J. (2018). Regularity extraction across species: Associative learning mechanisms shared by human and non-human primates. Topics in Cognitive Science. doi:10.1111/tops.12343

Rodríguez-Fornells, A., Cunillera, T., Mestres-Missé, A., \& de Diego-Balaguer, R. (2009). Neurophysiological mechanisms involved in language learning in adults. Philosophical Transactions of the Royal Society B: Biological Sciences, 364(1536), 3711-3735.

Saffran, J. R., Aslin, R. N., \& Newport, E. L. (1996). Statistical learning by 8-month-old infants. Science, 274, 1926-1928.

Schapiro, A. C., Gregory, E., Landau, B., McCloskey, M., \& Turk-Browne, N. B. (2014). The necessity of the medial temporal lobe for statistical learning. Journal of Cognitive Neuroscience, 26, 1736-1747. 
738 Schneider, W., Eschman, A., \& Zuccolotto, A. (2002) E-Prime user's guide. Pittsburgh, PA: 739 Psychology Software Tools Inc.

740 Siegelman, N., Bogaerts, L., Armstrong, B., \& Frost, R. (2019). What exactly is learned in 741 visual statistical learning? Insights from Bayesian modeling ? Cognition, 192, 104002.

742 Siegelman, N., Bogaerts, L., Christiansen, M., \& Frost, R. (2016). Towards a theory of 743 individual differences in statistical learning. Philosophical Transactions of the Royal $744 \quad$ Society - Biology, 372, 20160059.

745 Swingley, D. (2005). Statistical clustering and the contents of the infant vocabulary.

746 Cognitive Psychology, 50, 86-132.

747 Szmalec, A., Duyck, W., Vandierendonck, A., Mata, A. B., \& Page, M. P. A. (2009). The 748 Hebb repetition effect as a laboratory analogue of novel word learning. The Quarterly Journal of Experimental Psychology, 62(3), 435-443. doi:10.1080/17470210802386375

750 Thiessen, E. D., Kronstein, A. T., \& Hufnagle, D. G. (2013). The extraction and integration 751 framework: A two-process account of statistical learning. Psychological Bulletin, 139, $752 \quad 792-814$

753 Turk-Browne, N. B., Jungé, J. A., \& Scholl, B. J. (2005). The automaticity of visual 754 statistical learning. Journal of Experimental Psychology: General, 134(4), 552. 
REGULARITY DETECTION

757 Table 1

758 Means and Standard Deviations for Raw Speech Onset Latencies (SOLs) and Learning

759 Scores in Experiment 1

\begin{tabular}{lcccc}
\hline & Block 1 & Block 2 & Block 3 & Total \\
\hline Raw SOL & $411(68)$ & $382(67)$ & $376(71)$ & $389(70)$ \\
Position 1 & $413(73)$ & $388(67)$ & $364(84)$ & $388(77)$ \\
Position 2 & $415(67)$ & $389(73)$ & $376(72)$ & $393(72)$ \\
Position 3 & 0 & -.02 & .02 & \\
Learning score & 0 & & & \\
\hline
\end{tabular}

760

761

762 Table 2

763 Results of the Mixed Model for Experiment 1

\begin{tabular}{lccccc}
\hline \multicolumn{1}{c}{ Predictor } & $\beta$ & CI & SE & \multicolumn{2}{c}{$p$} \\
\hline (Intercept) & 390.3 & {$[376.3,404.3]$} & 7.1 & $<.001$ & $* * *$ \\
Position 2 & -1.9 & {$[-8.7,4.8]$} & 3.4 & .58 \\
Position 3 & 2.9 & {$[-4.8,10.6]$} & 3.9 & .47 \\
Repetition & -1.2 & {$[-1.7,-0.8]$} & 0.2 & $<.001$ & $* * *$ \\
Position 2: Repetition & -0.2 & {$[-0.5,0.1]$} & 0.2 & .14 & .99 \\
Position 3: Repetition & 0 & {$[-0.3,0.3]$} & 0.2 & \\
\hline
\end{tabular}

764 Note. Position was sum-coded.

765 
REGULARITY DETECTION

766 Table 3

767 Means and Standard Deviations for Raw Speech Onset Latencies (SOLs) and Learning

768 Scores in Experiment 2

\begin{tabular}{lcccc}
\hline & Block 1 & Block 2 & Block 3 & Total \\
\hline Raw SOL & $382(66)$ & $343(64)$ & $334(73)$ & $352(71)$ \\
Position 1 & $364(76)$ & $299(84)$ & $270(93)$ & $311(93)$ \\
Position 2 & $352(75)$ & $284(106)$ & $248(107)$ & $295(106)$ \\
Position 3 & .07 & .16 & .25 & \\
Learning score & & & & \\
\hline
\end{tabular}

769

770

$771 \quad$ Table 4

772 Results of the Mixed Model for Experiment 2

\begin{tabular}{lccccc}
\hline Predictor & $\beta$ & CI & $S E$ & $p$ & \\
\hline (Intercept) & 320.2 & {$[299.9,340.5]$} & 10.3 & $<.001$ & $* * *$ \\
Position 2 & -8.9 & {$[-17.2,-0.7]$} & 4.2 & .04 & $*$ \\
Position 3 & -24.3 & {$[-33.1,-15.4]$} & 4.5 & $<.001$ & $* * *$ \\
Repetition & -2.5 & {$[-3.3,-1.8]$} & 0.4 & $<.001$ & $* * *$ \\
Position 2: Repetition & -0.4 & {$[-0.8,-0.02]$} & 0.2 & .05 & $*$ \\
Position 3: Repetition & -0.8 & {$[-1.2,-0.3]$} & 0.2 & 0.004 & $* * *$
\end{tabular}

773

Note. Position was sum-coded.

774

775 
REGULARITY DETECTION

$776 \quad \underline{\text { Table } 5}$

777 Means and Standard Deviations for Raw Speech Onset Latencies (SOLs) and Learning

$778 \quad$ Scores in Experiment 3

\begin{tabular}{lcccc}
\hline & Block 1 & Block 2 & Block 3 & Total \\
\hline Raw SOL & $404(57)$ & $397(66)$ & $396(66)$ & $399(63)$ \\
Position 1 & $404(59)$ & $377(72)$ & $376(80)$ & $386(72)$ \\
Position 2 & $390(58)$ & $363(92)$ & $370(89)$ & $375(82)$ \\
Position 3 & .01 & .07 & .09 & \\
Learning score & & & & \\
\hline
\end{tabular}

779

780

$781 \quad \underline{\text { Table } 6}$

782 Results of the Mixed Model for Experiment 3

\begin{tabular}{lccccc}
\hline Predictor & $\beta$ & CI & $S E$ & $p$ & \\
\hline (Intercept) & 386 & {$[351,421]$} & 17.91 & $<.001$ & $* * *$ \\
Position 2 & -0.9 & {$[-5.6,3.7]$} & 2.37 & .71 & \\
Position 3 & -12.3 & {$[-23.7,-0.9]$} & 5.81 & .06 & \\
Repetition & -0.5 & {$[-1.4,0.35]$} & 0.45 & .26 & \\
Position 2: Repetition & -0.3 & {$[-0.68,0.09]$} & 0.19 & .16 & \\
Position 3: Repetition & -0.1 & {$[-0.64,0.44]$} & 0.28 & .72 & \\
\hline
\end{tabular}

Note. Position was sum-coded. 
REGULARITY DETECTION

784

$\underline{\text { Table } 7}$

785 Means and Standard Deviations for Raw Speech Onset Latencies (SOLs) and Learning

786 Scores in Experiment 4

\begin{tabular}{lcccc}
\hline & Block 1 & Block 2 & Block 3 & Total \\
\hline Raw SOL & & & & \\
Position 1 & $429(64)$ & $414(69)$ & $418(75)$ & $420(70)$ \\
Position 2 & $405(78)$ & $377(95)$ & $344(120)$ & $375(102)$ \\
Position 3 & $404(82)$ & $357(122)$ & $328(127)$ & $363(116)$ \\
Learning score & .08 & .21 & .34 & \\
\hline
\end{tabular}

787

788

789

$790 \quad \underline{\text { Table } 8}$

791 Summary of the Fixed Effects in the Mixed Model for Experiment 4

\begin{tabular}{lccccc}
\hline Predictor & $\beta$ & $\mathrm{CI}$ & $S E$ & $p$ & \\
\hline (Intercept) & 395.3 & {$[374.3,416.4]$} & 10.2 & $<.001$ & $* * *$ \\
Position 2 & -7.3 & {$[-14.9,0.4]$} & 3.8 & .07 & \\
Position 3 & -17.8 & {$[-30.6,-5]$} & 6.1 & $<.01$ & $* *$ \\
Repetition & -1.4 & {$[-2.2,-0.6]$} & 0.4 & $<.001$ & $* * *$ \\
Position 2: Repetition & -0.05 & {$[-0.3,0.2]$} & 0.14 & .74 & \\
Position 3: Repetition & -0.8 & {$[-1.4,-0.3]$} & 0.2 & $<.01$ & $* *$ \\
\hline
\end{tabular}

792 Note. Position was sum-coded.

793

794 
REGULARITY DETECTION

797 Figure 1. Density plot of speech onset latencies showing the fitted normal distribution in blue, 798 with a red line indicating our cut-off score.

799 Figure 2. Plot with smoothed estimate of mean speech onset times in Experiment 1 as a

800 function of letter position and number of repetitions. Grey-shaded areas indicate $95 \%$

801 confidence intervals around linear regression lines. Dashed lines represent the best linear fit.

802 Figure 3. Plot with smoothed estimate of mean speech onset times in Experiment 2 as a

803 function of letter position and number of repetitions. Grey-shaded areas indicate 95\%

804 confidence intervals around linear regression lines. Dashed lines represent the best linear fit.

805 Figure 4. Plot with smoothed estimate of mean speech onset times in Experiment 3 as a

806 function of letter position and number of repetitions. Grey-shaded areas indicate 95\%

807 confidence intervals around linear regression lines. Dashed lines represent the best linear fit.

808 Figure 5. Plot with smoothed estimate of mean speech onset times in Experiment 4 as a

809 function of letter position and number of repetitions. Grey-shaded areas indicate 95\%

810 confidence intervals around linear regression lines. Dashed lines represent the best linear fit.

811 Figure 6. Comparison of learning scores and their changes across repetitions for all-

812 consonant triplet in consonant-noise experiments. Grey-shaded areas indicate $95 \%$

813 confidence intervals around linear regression lines. Dashed lines represent the best linear fit. 
817

818

819

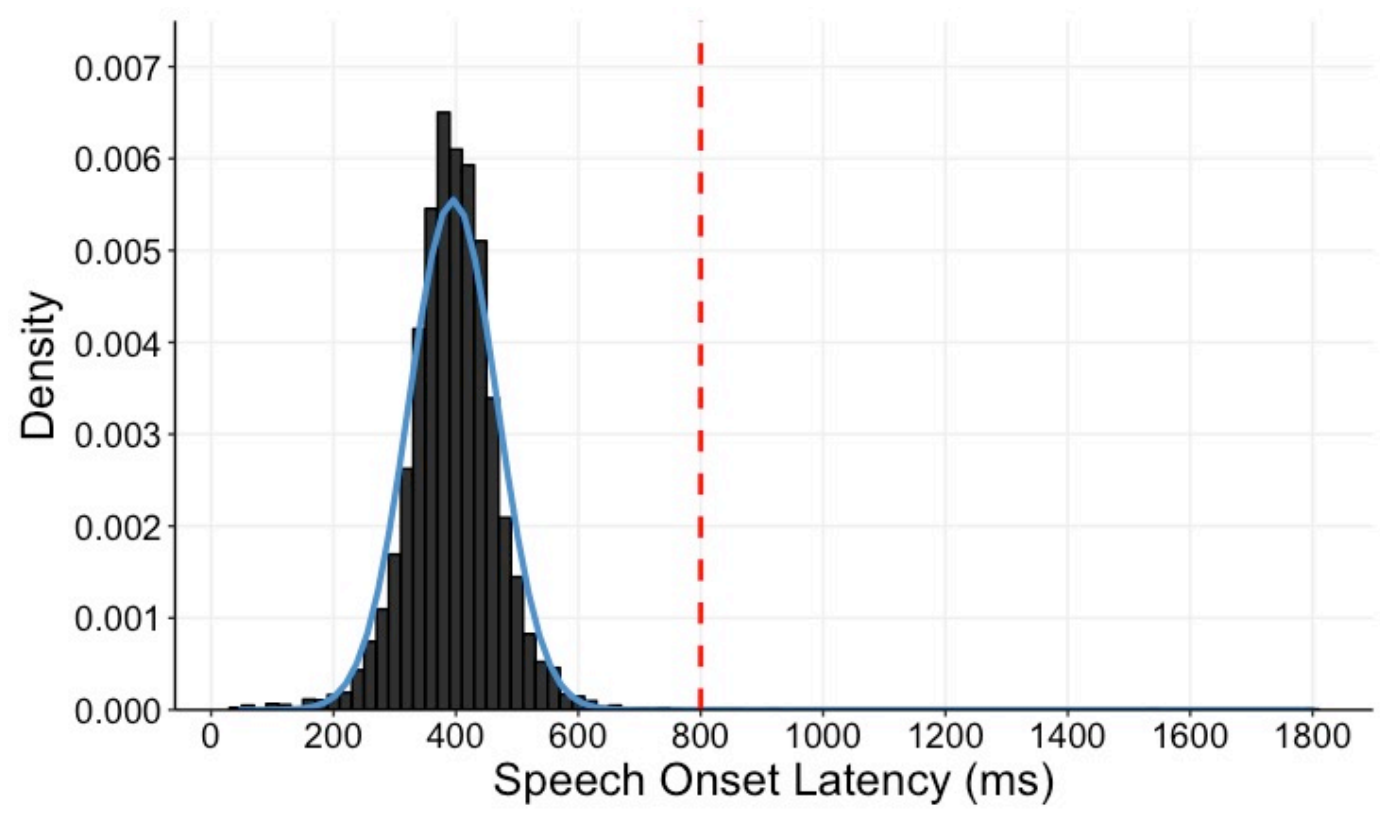

821

822

Figure 1

823 


\section{REGULARITY DETECTION}

824

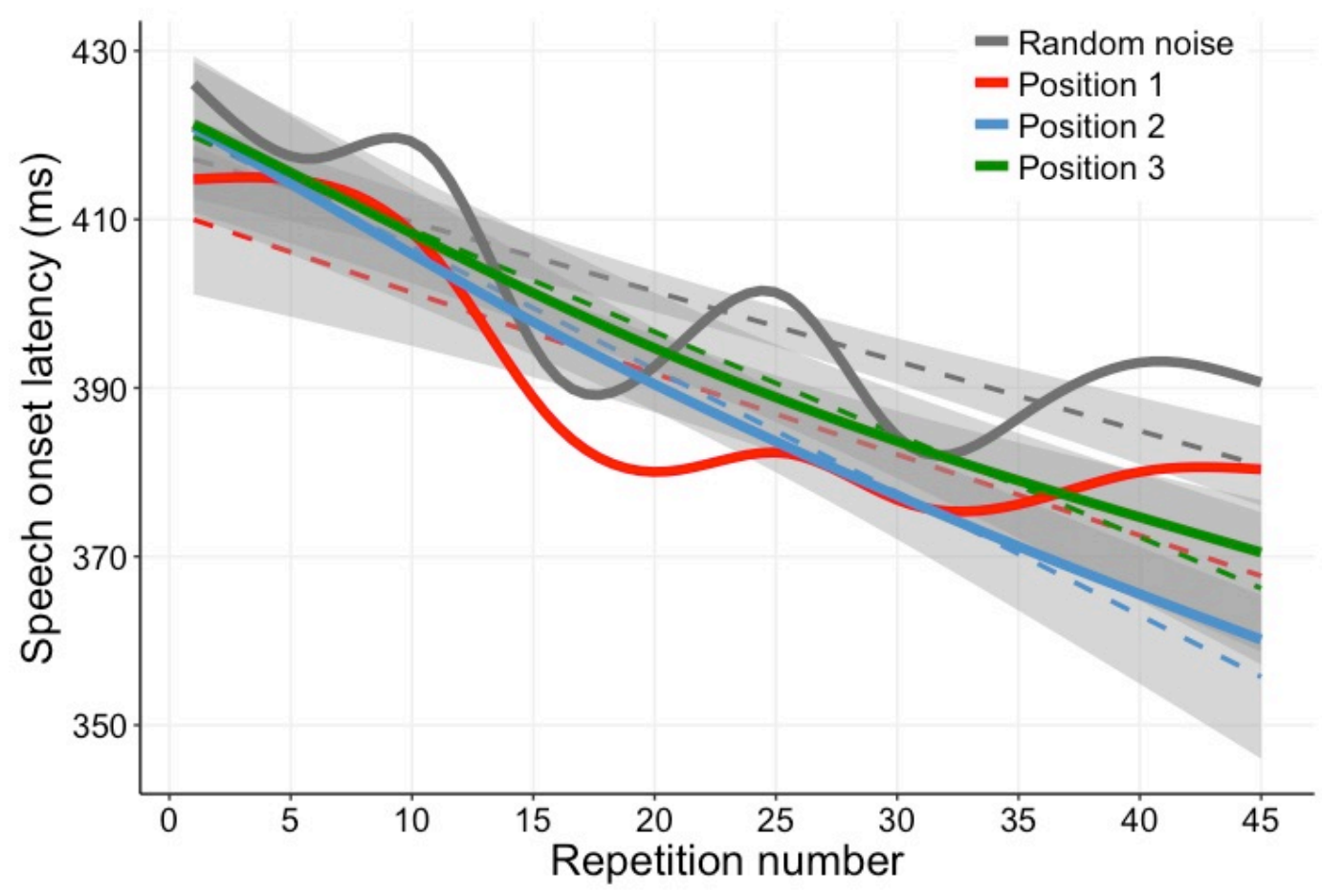

825

826

827

Figure 2 
828

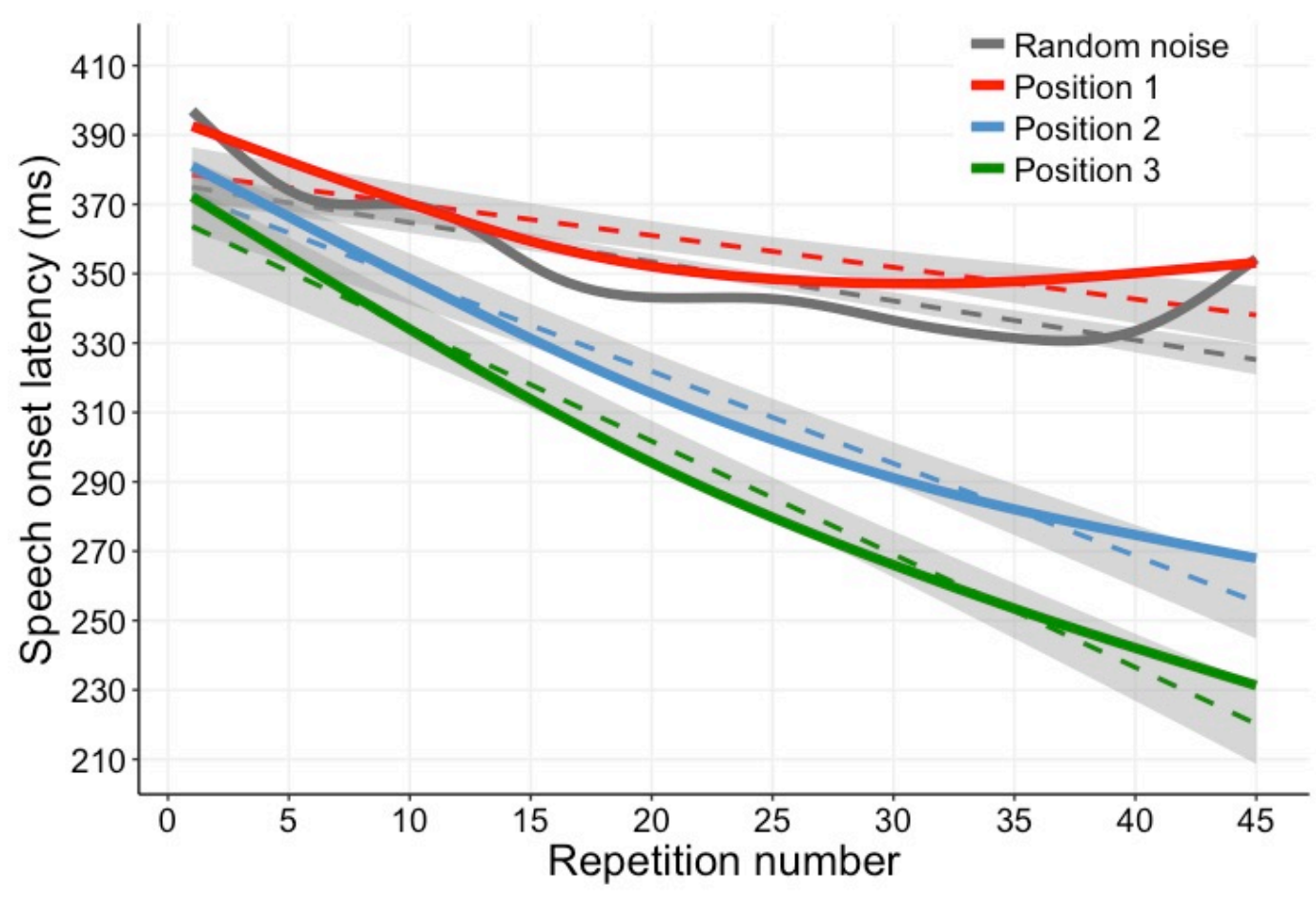

829

Figure 3

831

832

833

834 
835

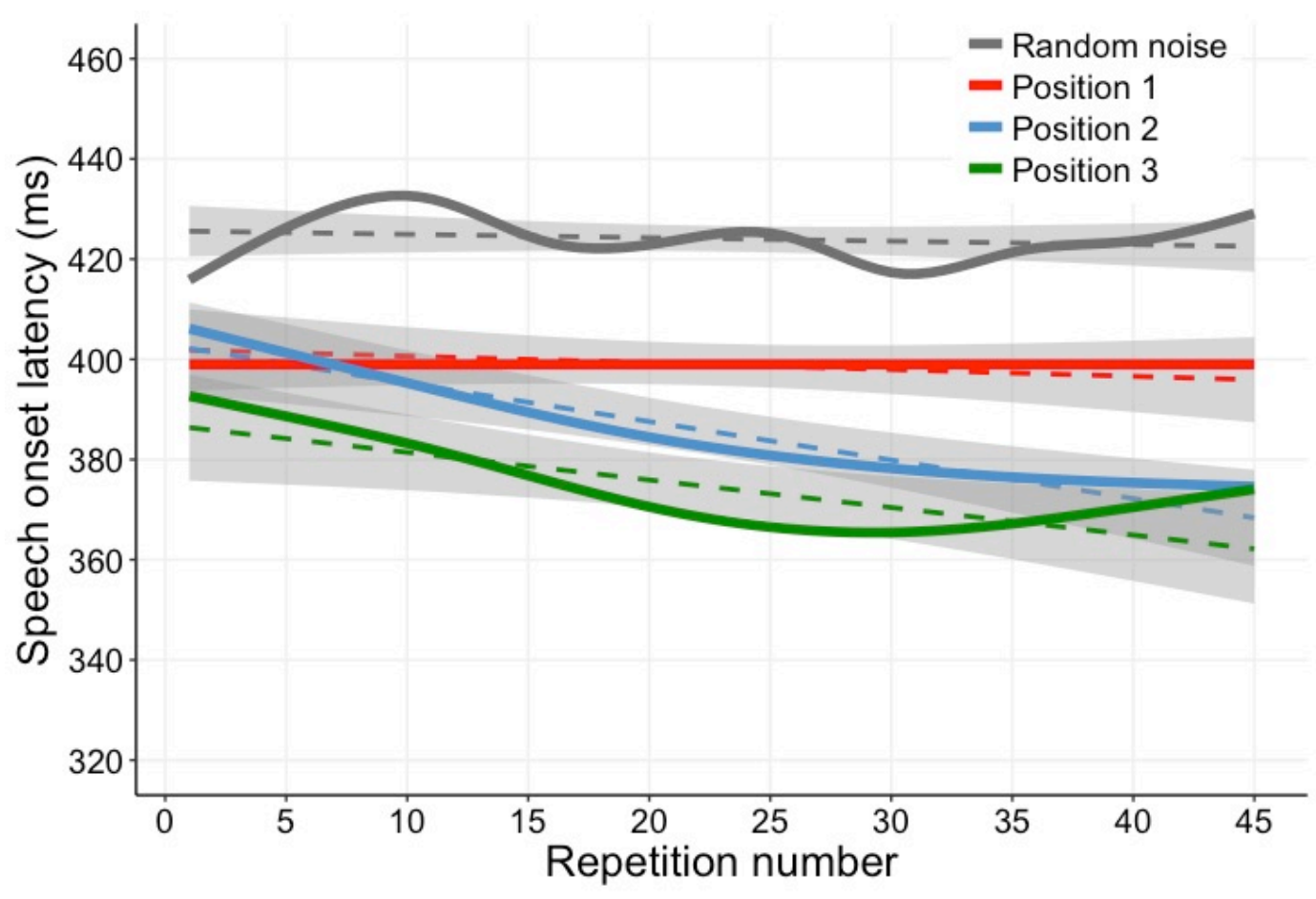

836

Figure 4

839

840 
841

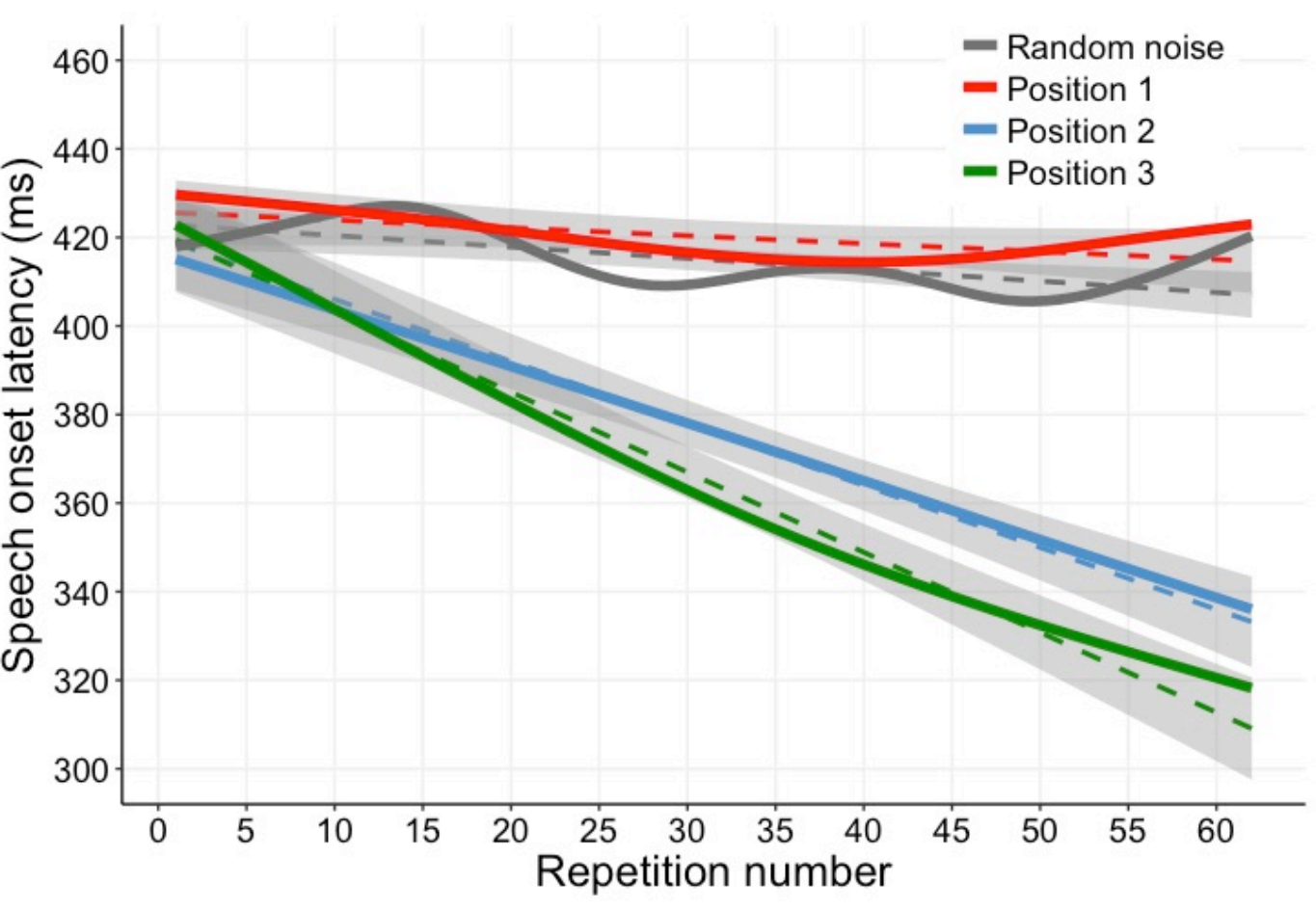

842

843

844

Figure 5

845

846 
847

848

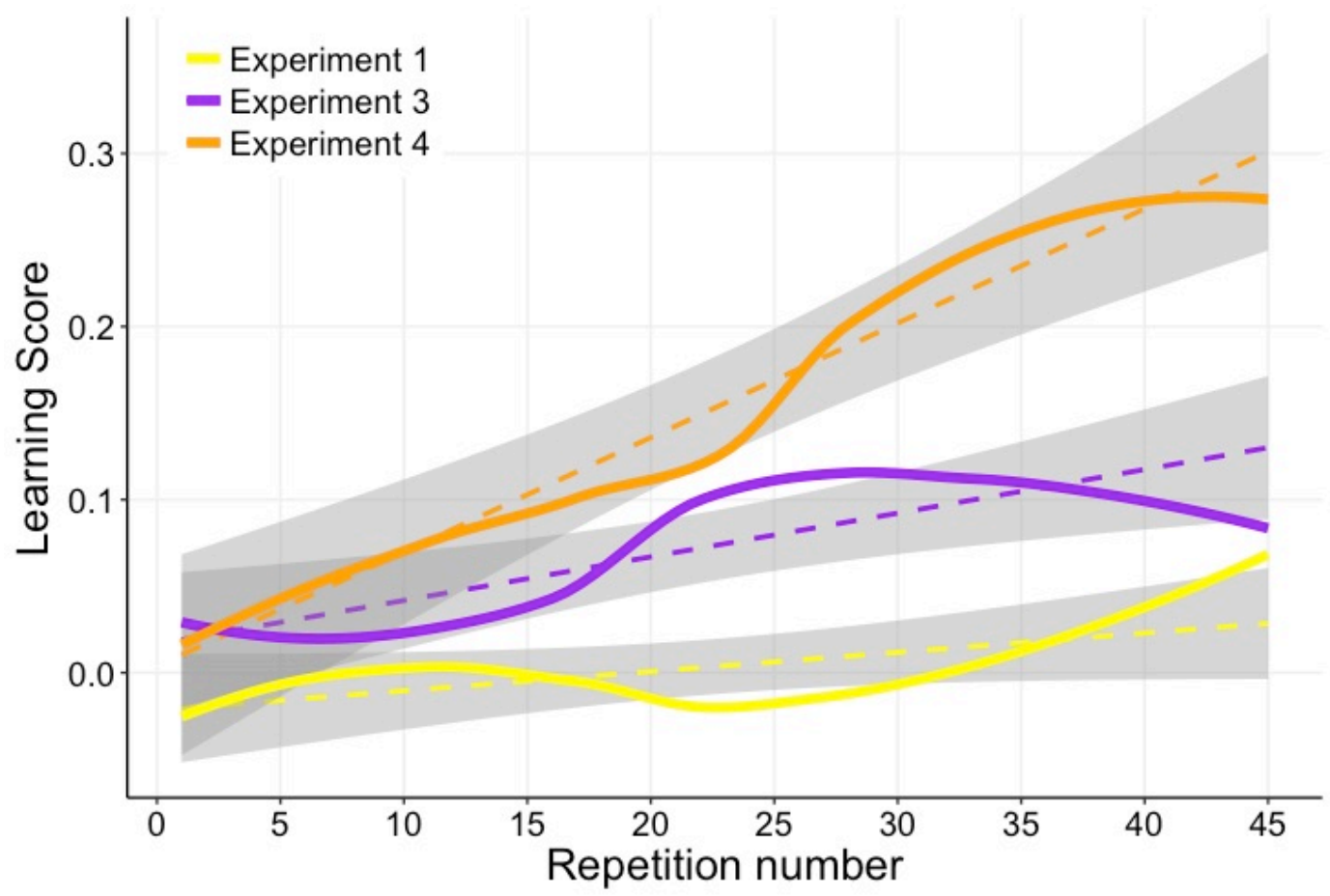

849

850

Figure 6

851

852

853

854 